\title{
Comparison of different estimation procedures for the hydraulic properties of horticultural substrates by One-Step technique
}

\author{
Carlo Bibbiani, ${ }^{1}$ Carlo A. Campiotti, ${ }^{2}$ Luca Incrocci, ${ }^{3}$ Alberto Pardossi ${ }^{3}$ \\ ${ }^{1}$ Department of Veterinary Science, University of Pisa, Italy; ${ }^{2}$ Department UTEE-AGR, ENEA, \\ Italy; ${ }^{3}$ Department of Agriculture, Food and Environment Science, University of Pisa, Italy
}

\begin{abstract}
The improved iterative method for the simultaneous determination of the hydraulic properties of growing media from One-Step experiment by Bibbiani, is performed and compared with simplified equations by Valiantzas and Londra. Brooks and Corey equation for water retention, and Kozeny power equation for hydraulic conductivity characterized the hydraulic properties of the porous media. The iterative procedure is applied on pure peat, pumice, and their mixes. The OneStep method has been previously optimized: processing the mean cumulative outflow curves recorded versus time, an estimation of diffusivity, and therefore of the hydraulic functions, is derived. Estimated water retention curve is compared with nine experimental data, and with the estimation of the Van Genuchten model, via the RETC code. Bibbiani's and Van Genuchten's models overlap except for the "very wet" range near saturation, whereas the Valiantzas and Londra's procedure didn't get satisfactory results. In regard to diffusivity, a good similarity between Bibbiani's and Van Genuchten-Mualem's curves can be assessed, while Valiantzas and Londra's procedure generally results in higher values. Due to the lack of estimation of the water retention curve, Valiantzas and Londra's procedure fails to estimate the hydraulic conductivity function, whereas Bibbiani's and Van Genuchten-Mualem's curves match together in most cases.
\end{abstract}

Correspondence: Carlo Bibbiani, Department of Veterinary Sciences, University of Pisa, Viale delle Piagge 2, 56124 Pisa, Italy.

Tel.: +39.050 .2216813 - Fax: +39.050 .2216706 .

E-mail: carlo.bibbiani@vet.unipi.it

Key words: hydraulic characteristics of substrates, parameter estimation, one-step experiment.

Contributions: the authors contributed equally.

(c) Copyright C. Bibbiani et al., 2013

Licensee PAGEPress, Italy

Journal of Agricultural Engineering 2013; XLIV(s2):e47

doi:10.4081/jae.2013.s2.e47

This article is distributed under the terms of the Creative Commons Attribution Noncommercial License (by-nc 3.0) which permits any noncommercial use, distribution, and reproduction in any medium, provided the original author(s) and source are credited.

\section{Introduction}

Water flow and solute transport modelling must rely on the knowledge of water retention and hydraulic conductivity curves, namely (h) and $K(\theta)$ or $K(h)$. Computed water balances are very sensitive to soil hydraulic parameters and therefore their accurate determination is essential (Jhorar et al., 2004; Schneider et al., 2009). Experimental methods have been set for this task, with varying complexity and accuracy of measurements. The substrate moisture retention curve is rather easily achieved. On the contrary, the determination of the hydraulic conductivity function requires the establishment of steadystate moisture profiles under unsaturated conditions, which is a tough assignment. This difficulty led scientists to conceptual models which could predict $K(\theta)$ from the moisture retention curve coupled by $K s$ measured independently (conductivity at saturation, where simple permeameters have been manufactured either constant head or falling head). Gardner (1962) introduced another method which relies on the determination of diffusivity $\mathrm{D}(\theta)$ relationship with one-step outflow data, being diffusivity the ratio of conductivity to the specific water capacity $\mathrm{C}(\mathrm{h})=\mathrm{d} / \mathrm{dh}$. Henceforth, many authors developed more accurate equations.

In this paper the cumulative outflow data obtained by one-step outflow experiment are used for the prediction of $D(\theta)$ employing equations from Valiatzas (1989), Bibbiani (2002), Valiantzas et al. (2007), Valiantzas and Londra (2012), and Van Genuchten-Mualem model (Mualem, 1976; Van Genuchten, 1980). Bibbiani's method, assuming a particular power form with a small number of parameters for the $\theta(h)$ and $K(h)$ curves, leads to the estimation of the hydraulic characteristics. The estimated hydraulic functions are compared with experimental data, and with the Van Genuchten-Mualem model curves.

\section{Materials and methods}

Five replications of peat, pumice, and a peat/pumice (1Pe:1Pu) [1:1 $(\mathrm{v} / \mathrm{v})$ ] mix were packed in $347.5 \mathrm{ml}$ cylindrical aluminum tubes $(7.6 \mathrm{~cm}$ in diameter, $7.6 \mathrm{~cm}$ in height). The pumice is a 'tout-venant' material sieved at $8 \mathrm{~mm}$ maximum particle size. At the end of the procedure, the substrate samples were seated on a grid for a 30 minutes 'free drainage'. Samples were then weighed to determine the water content $\theta_{\mathrm{fd}}$. At this time, samples were subjected to the One-Step procedure. Firstly, they were seated on the porous plates of Buchner filter funnels with an air-entry pressure $>16 \mathrm{kPa}$ and a plate conductivity equal to $2.28 \mathrm{~cm} / \mathrm{hr}$. An airtight lid was placed on the top of each funnel and a positive air pressure was applied. An initial pressure equal to $-1 \mathrm{kPa}$ referred to the core centre was applied; once equilibrium was reached, 
the core was weighed and replaced in the funnel, and a sudden application of a positive gas pressure increment marked the initiation of the outflow process recorded with time until equilibrium at the new pressure. The couple of pressure $[-1 ;-10] \mathrm{kPa}$ was chosen as it was the most accurate (Bibbiani, 2002). A duration of 48 hours proved to be sufficient to allow for the necessary equilibrium and calculations. To make a comparison with experimental moisture retention data, the above samples were resaturated: a drying retention curve was determined applying $-1.0 ;-2.0 ;-3.0 ;-5.0 ;-10.0 ;-15.0 ;-23.0 \mathrm{kPa}$ matric potential referred to the core centre. After $-23.0 \mathrm{kPa}$ measurement, the samples were removed and put in a ventilated oven at $105^{\circ} \mathrm{C}$ for 24 hours and weighed. Then, the cylinder was clamped in a constant volume air pycnometer device to determine the total porosity $\theta_{\text {TP. }}$ To measure saturated hydraulic conductivity, the modified constant head method described by Da Silva (1991) was followed in its main steps using Plexiglas $^{\mathrm{TM}}$ cylinder $(20.0 \mathrm{~cm}$ in height and $5.1 \mathrm{~cm}$ in diameter). The process was replicated three times. The mean value was taken as the saturated hydraulic conductivity Ks.

In order to calculate $\mathrm{D}(\theta)$ function, Valiantzas (1989) derived an accurate equation, starting from Gardner (1962) and Passioura (1976) approximate equations, as:

$$
\mathrm{D}(\theta)=-\frac{2 \cdot L^{2}}{\pi^{2}}\left(\frac{d q}{d \theta}+\frac{q}{\theta-\theta_{f}}\right)
$$

where $q=d \theta / d t$ is the outflow rate, $\theta_{\mathrm{f}}$ is the final volumetric water content in One-Step experiment, and $\mathrm{L}$ is the height of the sample. Valiantzas et al. (1988), and Valiantzas and Kerkides (1990) proposed a simple method for the simultaneous determination of hydraulic properties starting from an estimation of diffusivity function $\mathrm{D}(\theta)$. Bibbiani (2002), in order to remove the limitation due to the absence of the $\theta \mathrm{r}$ parameter, re-introduced the latter in the relative water content equation. Thus, the proposed $\Theta$ equations are written as:

Brooks and Corey's (B\&C, as referred herein after), for water retention

$$
\begin{array}{ll}
\Theta=\left[\frac{H e}{h}\right]^{\lambda} & \mathrm{h}>\mathrm{He} \\
\Theta=\frac{\theta-\theta \mathrm{r}}{\theta \mathrm{S}-\theta \mathrm{t}}=1 & 0 \leq \mathrm{h} \leq \mathrm{He}
\end{array}
$$

Kozeny's (KO, as referred herein after), for conductivity

$$
\mathrm{Kr}(\Theta)=\frac{K(\Theta)}{K_{S}}=(\Theta)^{\mathrm{p}}
$$

where $\theta s$ is the saturated water content, $\theta r$ is the residual water content, He is the air-entry value, $\mathrm{p}$ and $\lambda$ are fitting parameters.

Eqs. 2, 3, and 4 can be substituted for $\mathrm{D}(\Theta)$ equation obtaining:

$$
\begin{aligned}
& \mathrm{D}(\Theta)=\mathrm{B} \cdot(\Theta)^{\mathrm{A}} \\
& \mathrm{B}=\frac{\mathrm{Ks} H \mathrm{He}}{\lambda(\theta \mathrm{s}-\theta \mathrm{r})} \\
& \mathrm{A}=\mathrm{p}-1-\frac{1}{\lambda}
\end{aligned}
$$

The problem appears as an identification problem of parameters A, $\mathrm{B}, \lambda$, and $\theta \mathrm{r}$, while $\theta \mathrm{s}$ is taken as a known parameter, and calculated in this paper as:

$$
\theta \mathrm{s}=\frac{3 \theta_{T P}+\theta_{\mathrm{fd}}}{4}
$$

The outflow rate $\mathrm{q}(\theta(\mathrm{t}))$ is related to diffusivity $\mathrm{D}(\theta)$ by approximate analytical expressions, $\lambda(\mu)$ and $\theta_{\mathrm{L}}(\mu), \mu$ depending on $(\theta ; \theta$ r; A), as proposed by Valiantzas and Kerkides (1990) and modified by Bibbiani (2002):

$$
\mathrm{g}(\theta)=\frac{\mathrm{B} \cdot \lambda^{*}(\mu)}{(\mathrm{A}+1) \cdot \mathrm{L}^{2}(\theta \mathrm{S}-\theta \mathrm{r})^{\mathrm{A}}} \cdot\left[\left(\theta_{\mathrm{L}}(\mu)^{-\theta r}\right)^{\mathrm{A}+1}-(\theta \mathrm{f}-\theta \mathrm{r})^{\mathrm{A}+1}\right]
$$

Each $\theta$ r value leads to estimate parameters A and B minimizing the difference between simulated and measured outflow rates $q(t)$. Consequently the $D(\theta)$ function is calculated. Then, the unknown parameter $\lambda$ is estimated minimizing the $S(\theta r, \lambda)$ objective function, which is the difference between the natural logarithm of measured and simulated relative water content data, calculated as:

$$
\mathrm{S}(\theta \mathrm{r}, \lambda)=\sum_{\mathrm{y}=1}^{\mathrm{M}}\left\{\ln \left[\frac{\theta y-\theta \mathrm{r}}{\theta \mathrm{s}-\theta \mathrm{r}}\right]-\lambda \cdot \ln \left[\frac{\lambda(\theta \mathrm{s}-\theta \mathrm{t})}{\mathrm{Ks}} \mathrm{B}_{(\theta) \mathrm{C}}\right]+\lambda \cdot \ln \left[\left[\mathrm{h}_{\mathrm{y}}\right]\right\}^{2}(10)\right.
$$

where $M$ means number of experimental $\theta(\mathrm{h})$ data, $\theta_{\mathrm{y}}$ is the water content in correspondence with $\mathrm{h}_{\mathrm{y}}$ value of matric potential.

Thus, the minimum value function $S(\theta r, \lambda)$ can be plotted, and its minimum singles out the best fitting vector $\left[\theta_{\mathrm{r}}, \lambda_{\mathrm{r}}\right]$. Eq. 6 and 7 give parameters He and p, and so functions $\theta(h)$ and $K(h)$ are plotted. In order to neglect the porous plate impedance effect on the results, which might be significant at the early stages of the outflow process, Valiantzas et al. (1988) forced the procedure for estimating $\mathrm{D}(\theta)$ analyzing only the part of the curve where the cumulative outflow $\mathrm{V}$ ceases to be linear with respect to the square root of time $\sqrt{ }$ t. Later on, Valiantzas et al. (2007) and Valiantzas and Londra (2012) derived some simplified equation for the determination of the hydraulic properties of horticultural substrates, applying respectively Eq. 1 in the former, and B\&C equation and Burdine model (Burdine, 1953) in the latter; they introduced in Eq. 1 a new dimensionless variable obtained from the outflow data as well, the fraction of the remaining outflow water volume $S_{\text {out }}$, as:

$$
\mathrm{S}_{\text {out }}=\frac{\theta-\theta_{\mathrm{f}}}{\theta_{\mathrm{i}}-\theta_{\mathrm{f}}}=\mathrm{F} \cdot(\sqrt{ } \mathrm{t})^{\mathrm{G}}
$$

which is related to cumulative outflow $V$ vs. the square root of time $\sqrt{t}$ with a power form similar to that of Eq. 5, where $\theta_{\mathrm{i}}$ and $\theta_{\mathrm{f}}$ are respectively the initial and final volumetric water content in One-Step experiment, $\mathrm{F}$ and $\mathrm{G}$ are fitting parameters. In this context, they derived the following:

$$
\mathrm{D}(\theta)=-\frac{2 \cdot(G-1) \cdot L^{2} \cdot F^{2} / G}{\pi^{2}}\left(\frac{\theta-\theta f}{\theta i-\theta f}\right)^{-2 / G}
$$

In order to evaluate the hydraulic functions, they proposed to measure experimentally the water retention, or alternatively, in their latter paper, to run the One-Step procedure fixing $\theta_{\mathrm{f}}$ as close as possible to the 'real' $\theta_{\mathrm{r}}$ value.

In the present paper, in order to compare all the previous estimated water retention and hydraulic conductivity curves, the Van GenuchtenMualem (VG-M, as referred herein after) combined model (Mualem, 1976; Van Genuchten, 1980) was applied to experimental retention 
data, having fixed their parameters respectively as $\mathrm{m}=1-1 / \mathrm{n}, \mathrm{l}=0.5$, and $\theta$ s from Eq. 8. The fitting program RETC (Van Genuchten et al., 1991) estimated $\theta \mathrm{r}, \alpha$, and $\mathrm{n}$ unknown parameters, computing both experimental retention data coming only from One-Step experiment and diffusivity data calculated by Eq. 5 .

$$
\begin{aligned}
& \Theta(h)=\frac{\theta-\theta r}{\theta s-\theta r}=\left[1+(\alpha \cdot|h|)^{n}\right]^{m} \\
& \mathrm{C}(\Theta)=\alpha n m\left(\theta_{s}-\theta_{r}\right) \Theta^{1 / \mathrm{m}}\left(1-\Theta^{1 / \mathrm{m}}\right)^{\mathrm{m}}
\end{aligned}
$$

$$
\begin{aligned}
& \mathrm{K}(\Theta)=\mathrm{Ks} \cdot \Theta^{1 / 2}\left[1-\left(1-\Theta^{1 / m}\right)^{m}\right]^{2} \\
& \mathrm{D}(\theta)=\frac{K(\Theta)}{C(\Theta)}
\end{aligned}
$$

Finally, RETC code estimated $\mathrm{D}(\theta)$ taking as input only 9 experimen-

\begin{tabular}{|c|c|c|c|c|c|}
\hline \multicolumn{2}{|c|}{ Pure Peat } & \multicolumn{2}{|c|}{ 1Peat:1Pumice } & \multicolumn{2}{|c|}{ Pure Pumice } \\
\hline $\begin{array}{l}\text { Pressure } \\
\text { Head h }\end{array}$ & $\begin{array}{c}\text { Water } \\
\text { Content } \theta\end{array}$ & $\begin{array}{l}\text { Pressure } \\
\text { Head h }\end{array}$ & $\begin{array}{c}\text { Water } \\
\text { Content } \theta\end{array}$ & $\begin{array}{l}\text { Pressure } \\
\text { Head h }\end{array}$ & $\begin{array}{c}\text { Water } \\
\text { Content } \theta\end{array}$ \\
\hline $3.8={ }^{\prime} \theta \mathrm{fd}{ }^{\prime}$ & 0.879 & $3.8=$ ' ' $\theta f d '$ & 0.729 & $3.8=$ ' $\theta \mathrm{fd}^{\prime}$ & 0.465 \\
\hline $3.8={ }^{\prime} \theta \mathrm{fd}{ }^{\prime}$ & 0.879 & $3.8=$ ' '$\theta \mathrm{fd} '^{\prime}$ & 0.729 & $3.8=$ ' $\theta \mathrm{fd}$ ' & 0.465 \\
\hline 20 & 0.501 & 20 & 0.525 & 20 & 0.380 \\
\hline 30 & 0.435 & 34 & 0.471 & 30 & 0.370 \\
\hline 50 & 0.379 & 50 & 0.447 & 50 & 0.364 \\
\hline $104={ }^{\prime} \theta \mathrm{f}^{\prime}$ & 0.329 & $104={ }^{\prime} \theta f^{\prime}$ & 0.395 & $100={ }^{\prime} \theta f^{\prime}$ & 0.347 \\
\hline 140 & 0.318 & 147 & 0.376 & 140 & 0.340 \\
\hline 230 & 0.309 & 233 & 0.361 & 230 & 0.335 \\
\hline
\end{tabular}
tal moisture retention data, thus resulting in the VG-M (Retention only) curve.

\begin{tabular}{|c|c|c|c|c|c|c|c|c|}
\hline Substrate & $\begin{array}{c}\rho \\
\mathrm{kg} \mathrm{m}^{-3}\end{array}$ & $\begin{array}{c}\theta_{\mathrm{TP}} \\
\mathrm{m}^{3} \mathrm{~m}^{-3}\end{array}$ & $\begin{array}{c}\theta \mathrm{s} \\
\mathrm{m} 3 \mathrm{~m}^{-3}\end{array}$ & $\begin{array}{c}\mathrm{Ks} \\
\mathrm{cm} \mathrm{min}^{-1}\end{array}$ & $\begin{array}{c}\bar{\theta}_{r} \\
m^{3} m^{-3}\end{array}$ & $\mathbf{A}\left(\bar{\theta}_{r}, \lambda\right)$ & $\mathbf{A}\left(\bar{\theta}_{\mathrm{r}}, \lambda\right)$ & $\lambda$ \\
\hline Peat & 115 & 0.94 & 0.92 & 3.360 & 0.298 & 2.7498 & 33.8752 & 1.1285 \\
\hline 1Pe:1Pu & 307 & 0.86 & 0.83 & 1.44 & 0.206 & 6.1897 & 19.715 & 0.3315 \\
\hline Pumice & 830 & 0.68 & 0.62 & 180.0 & 0.248 & 6.827 & 100.75 & 0.1665 \\
\hline
\end{tabular}

Table 1. Water retention data-sets, and One-Step pressure heads set-up.

Table 2. Measures parameters at saturation, and parameter estimation obtained for Eqs. 2-7. B\&C-KO model.

\begin{tabular}{|c|c|c|c|c|c|c|}
\hline \multirow{2}{*}{ Variable } & \multicolumn{2}{|c|}{ Pure Peat } & \multicolumn{2}{|c|}{ 1Peat:1Pumice } & \multicolumn{2}{|c|}{ Pure Pumice } \\
\hline & Value & St.dev. & Value & St.dev. & Value & St.dev. \\
\hline \multicolumn{7}{|c|}{ Parameter for Eq. 12} \\
\hline $\mathrm{F}$ & 6.793 & & 10.13 & & 324.2 & \\
\hline $\mathrm{G}$ & -1.767 & & -1.433 & & -2.439 & \\
\hline \multicolumn{7}{|c|}{ Fit of 9 experimental retention data only for Eq. 13} \\
\hline$\theta r$ & 0.3030 & 0.0058 & 0.2907 & 0.0102 & 0.3283 & 0.0091 \\
\hline$\alpha$ & 0.1042 & 0.0030 & 0.2348 & 0.0113 & 0.8385 & 0.2135 \\
\hline $\mathrm{n}$ & 2.3396 & 0.0700 & 1.5093 & 0.0298 & 1.6297 & 0.1234 \\
\hline $\mathrm{m}$ & 0.5725 & & 0.3374 & & 0.3864 & \\
\hline R2 & 0.9993 & & 0.9995 & & 0.9964 & \\
\hline \multicolumn{7}{|c|}{ Simultaneous fit of retention and diffusivity data from One-Step experiment for Eq. 13} \\
\hline$\theta_{\mathrm{r}}$ & 0.3072 & 0.0007 & 0.3069 & 0.0074 & 0.2788 & 0.0040 \\
\hline$\alpha$ & 0.0984 & 0.0015 & 0.7149 & 0.0782 & 2.7400 & 0.1434 \\
\hline $\mathrm{n}$ & 2.3681 & 0.0244 & 1.3873 & 0.0221 & 1.2906 & 0.0093 \\
\hline $\mathrm{m}$ & 0.5777 & & 0.2792 & & 0.2252 & \\
\hline $\mathrm{R}^{2}$ & 0.9993 & & 0.9541 & & 0.9923 & \\
\hline
\end{tabular}

Table 3. Parameter estimation obtained for Eq. 12. Nonlinear least-squares analysis by RETC program $(1=0.5)$. Fit of 9 experimental retention data only for Eq. 13. VG-M (Retention only) model. Simultaneous fit of Retention and Diffusivity data from One-Step experiment for Eq. 13. VG-M model. 
A

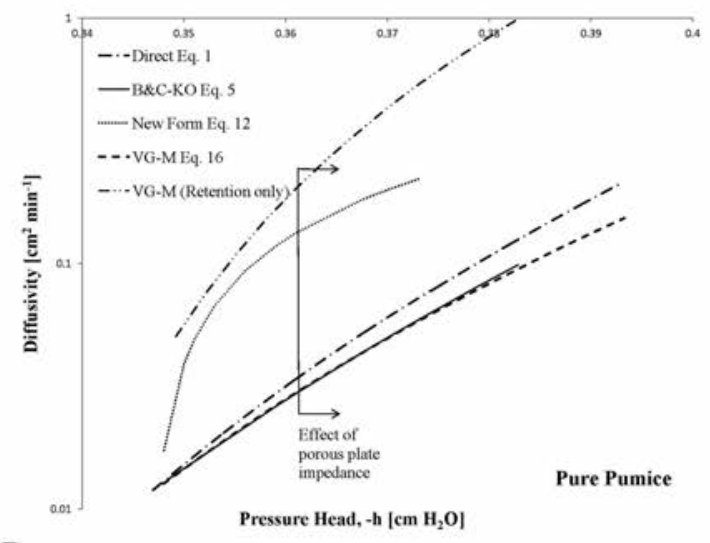

B

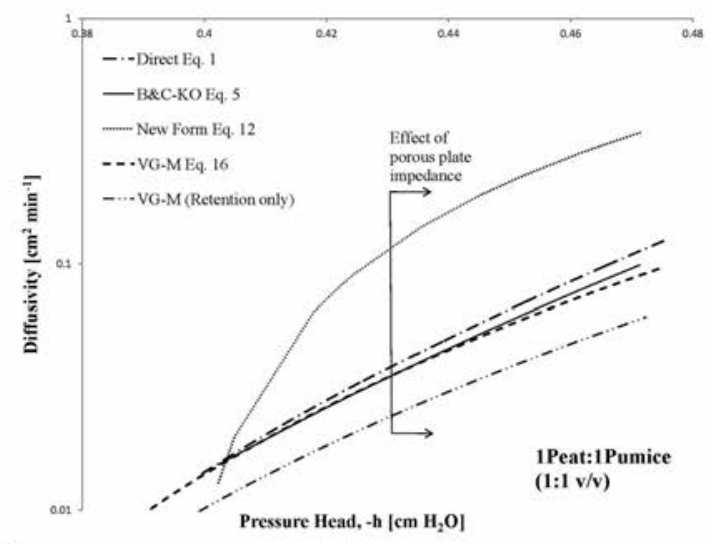

$\mathrm{C}$

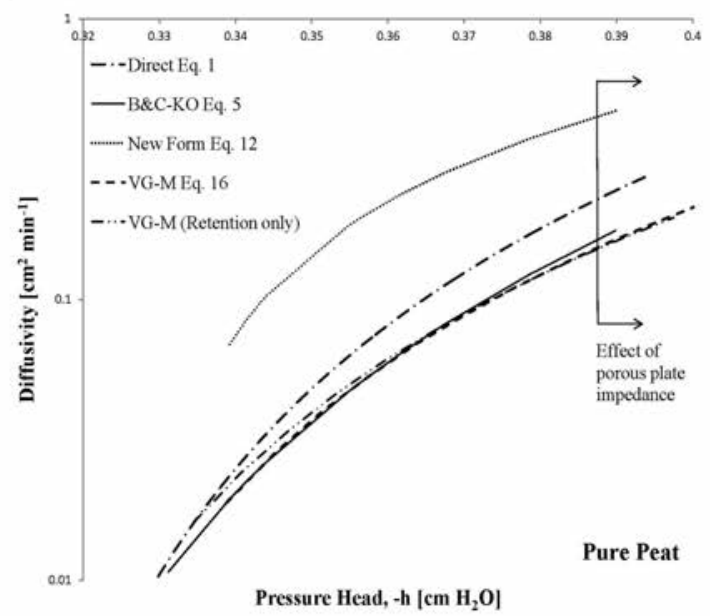

Figure 1. Substrate water diffusivity as a function of volumetric water content, $\mathbf{D}(\theta)$, estimated by various equations. (A). Pure Pumice (B). 1Peat:1Pumice (1:1 v/v) (C). Pure Peat. The short vertical line labeled "Effect of the porous plate impedance" defines the region where the plate impedance is not negligible.
A

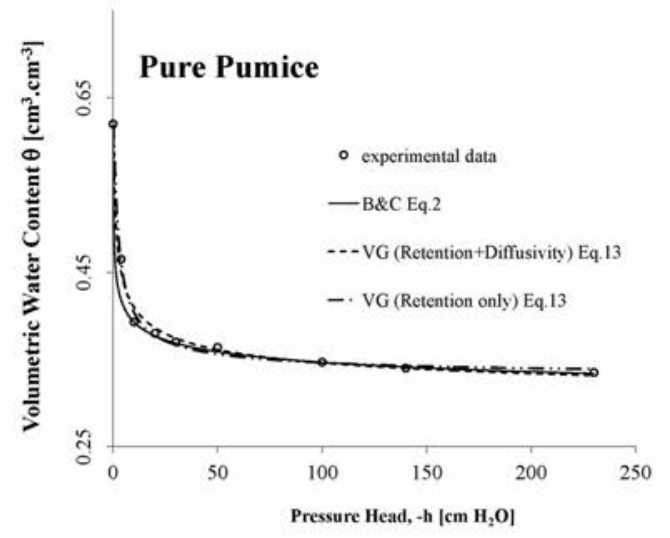

B

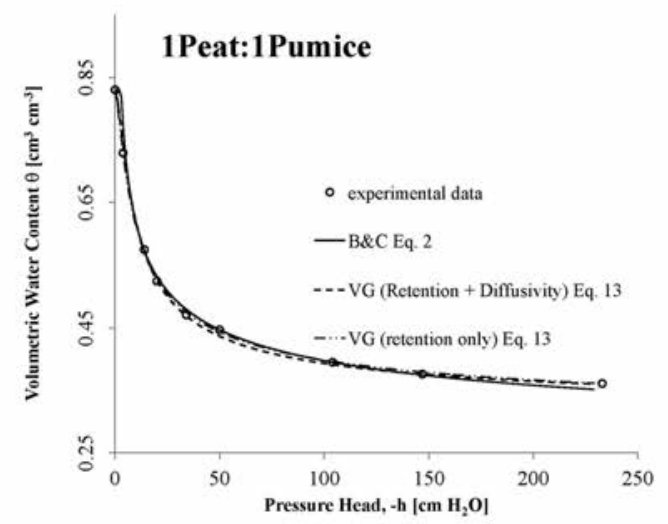

$\mathrm{C}$

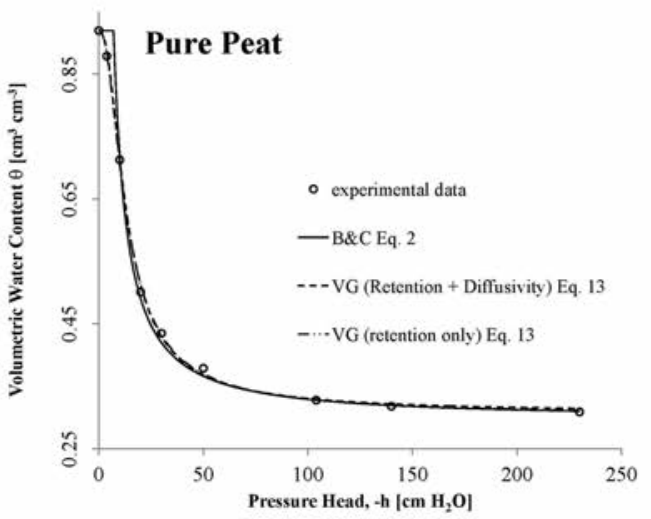

Figure 2. Substrate water retention $\theta(h)$ as a function of pressure head $-\mathbf{h}$, measured and estimated by B\&C and VG equations. (A). Pure Pumice (B). 1Peat:1Pumice (1:1 v/v) (C). Pure Peat. 


\section{Results and discussion}

Table 1 reports all the measured moisture retention points for the three substrates, and the initial and final pressure heads set-up for One-Step experiment. Table 2 shows the estimated parameters for Eqs. 2 and 5 , as related to the B\&C-KO model improved by Bibbiani (2002).

Table 3 refers to Eq. 12, giving parameters of the new dimensionless variable $S_{\text {out }}$, obtained by Valiantzas et al. (2007). Moreover, it reports the estimation by RETC code for the VG-M model related to Eq. 13, with the analysis of 9 retention data only (derived from independent measurements), and both retention and diffusivity data derived from OneStep experiment. A comparison of diffusivity functions, $D(\theta)$, estimated by the above discussed equations, is well-drawn in Figure 1. Irrespective to the substrate nature, there is a good agreement between the direct calculation of $\mathrm{D}(\theta)$ by Eq. 1, and both the B\&C-K0 model by Eq. 5 and the VG-M model by Eq. 16 (retention and diffusivity data). The VG-M (Retention only) curve shows a variable and unpredictable behavior, suggesting a non-reliable estimation based only on retention data. The prediction of $\mathrm{D}(\theta)$ by Eq. 12 doesn't match any other ones in this experiment. Since Valiantzas et al. (2007) reported a substantial identity between their estimation and Eq. 1, the huge discrepancy in the present work might depend on the different final pressure at the end of the outflow procedure $\mathrm{h}\left(\theta_{\mathrm{f}}\right)$ that they fixed in the range $-14 \div-18$ $\mathrm{kPa}$. Doing this way, they assumed that $\theta_{\mathrm{f}}$ is very close to the $\theta_{\mathrm{r}}$ value, thus letting the estimation of $\theta_{r}^{0}$; on the contrary, in this paper, $\mathrm{h}\left(\theta_{\mathrm{f}}\right)$ was chosen by analogy to the well-known tension range for the calculation of the hydraulic properties of horticultural substrates, such as the 'easy available water' value. On the basis of these results, the comparison of the water retention function gives us a deeper understanding of the whole estimation capability. Figure 2 shows the experimental data, the B\&C and VG plot of the function, as well. As one can see, the main difference between B\&C Eq. 2 and VG Eq. 13 estimated curve lies in the very wet range (i.e. $h(\theta)<-1 \mathrm{kPa}$ ), being all the rest almost overlapped. Both the predictions by Valiantzas et al. (2007) and Valiantzas and Londra (2012) don't match the experimental water retention results (data not shown), most likely because of the same reason above explained. Moreover, the B\&C Eq. 2 model, related only to One-Step procedure, seems to have the same power of estimation of the VG Eq. 13 model, both of them being in optimal agreement with the experimental water retention data.

Figure 3 provides us information about the sensitivity of Eq. 16 calculating $K(\theta)$ as unknown variable. In fact, despite the large difference between the estimation of $\mathrm{D}(\theta)$ with VG-M (retention and diffusivity data) and VG-M (retention only) curve by Eq. 15, the influence of the specific water capacity $\mathrm{C}(\mathrm{h})$, being the first derivative of the $\theta(\mathrm{h})$ curve, results in a much narrow gap between the respective $K(\theta)$ curves. In fact, except for the VG-M (retention only) model applied to Pure Pumice, which leads to a remarkable discrepancy in the wet range, the estimated functions are close to each other, relatively to each substrate. In this respect, the RETC code computation of experimental data coming only from One-Step procedure provides a sound basis comparison with the improved iterative method by Bibbiani (2002).

\section{Conclusions}

This study aims to compare different methods for the simultaneous determination of the hydraulic properties of growing media from OneStep experiment, exploiting the capability of the latter procedure to estimate the diffusivity function. Valiantzas et al. $(1988,1990,2007)$ and Valiantzas and Londra (2012) set up attractive equations for this task. From their approach stems the Bibbiani (2002) improvement of the estimation method, based on Brooks and Corey equation for water retention, and Kozeny power equation for hydraulic conductivity. An independent set of 9 water retention experimental data allows the comparison of estimated curves. Moreover, the RETC software with the Van Genuchten model is performed, resulting in other two estimations of the hydraulic function: the first one coming only from water retention experimental data, the second one computing retention and diffusivity

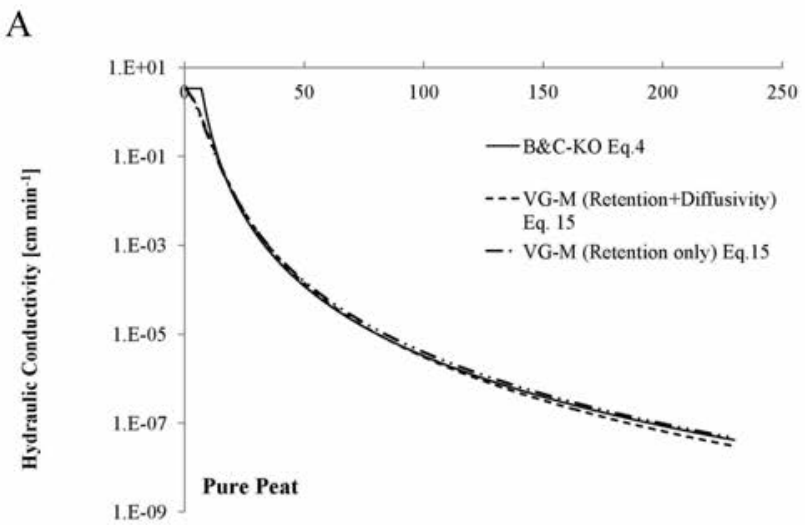

B

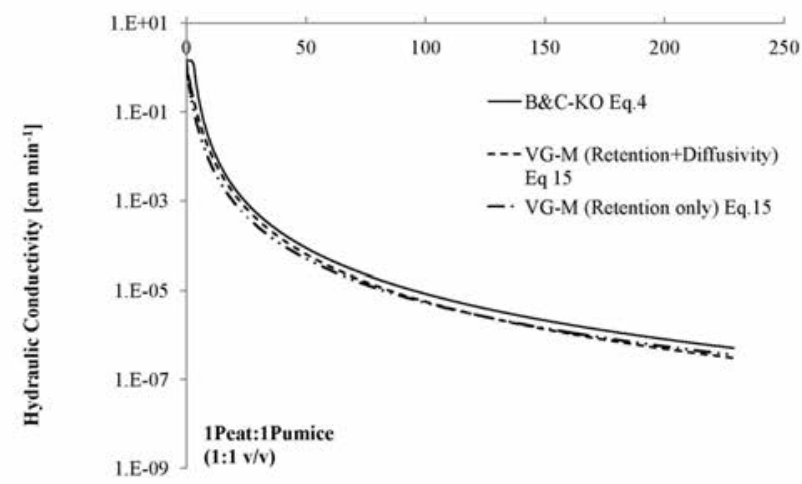

$\mathrm{C}$

Pressure Head, -h $\left[\mathrm{cm} \mathrm{H} \mathrm{H}_{2} \mathrm{O}\right]$

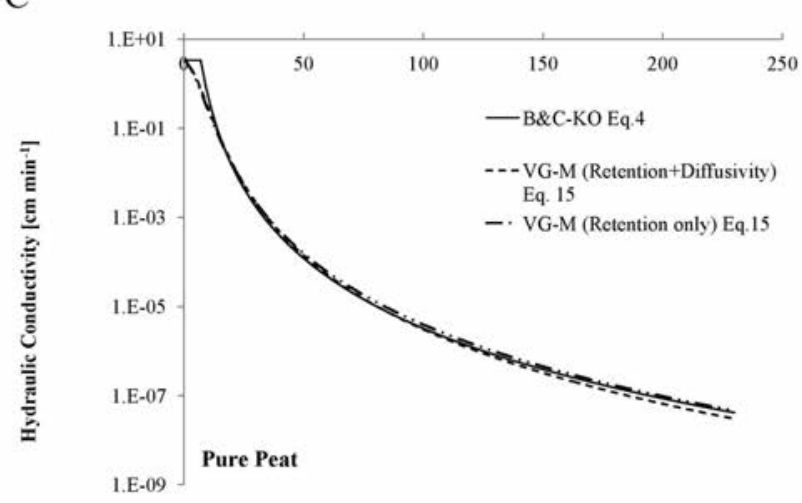

Pressure Head, -h $\left[\mathrm{cm} \mathrm{H}_{2} \mathrm{O}\right]$

Figure 3. Substrate water conductivity $K(h)$ as a function of pressure head -h, estimated by various equations. (A). Pure Pumice (B). 1Peat:1Pumice $(1: 1 \mathrm{v} / \mathrm{v})(\mathrm{C})$. Pure Peat. 
data from One-Step experiment.

Due to different requirements related to the final pressure head applied in One-Step experiment, Bibbiani's method leads to a good estimation of hydraulic functions for the three horticultural substrates in agreement with the Van Genuchten model, while the Valiantzas and Londra (2012) set of equations show poor applicability to this particular choice of the final pressure head.

\section{References}

Bibbiani C. 2002. An iterative procedure to estimate hydraulic characteristic of plant substrates from One-Step outflow data. Agricoltura Mediterranea 132:232-245.

Burdine, N.T. 1953. Relative permeability calculation from pore size distribution data. Trans. Am. Inst. Min. Eng., 198, 71-78.

Da Silva F.F. 1991. Static and dynamic characterization of container media for irrigation management. Thesis for MSc, Faculty of Agriculture; Hebrew University of Jerusalem.

Gardner W.R. 1962. Note on the separation and solution of diffusion type equation. Soil Sci. Soc. Am. Proc. 26, 404.

Johrar R. K., van Dam J. C., Bastiaansan W. G. M., Feddes R. A. 2004. Calibration of effective soil hydraulic parameters of heterogeneous soil profiles, J. Hydrol., 285, 233-247.

Mualem Y. 1976. A new model for predicting the hydraulic conductivity of unsaturated porous media. Water Resour. Res. 12:513-522.

Passioura J.B. 1976. Determining soil water diffusivity from one-step outflow experiments. Aust. J. of Soil Res. 15, 1-8.
Schneider C.L., Attinger S., Delfs J.0., Hildebrandt A. 2009. Implementing small scale processes at the soil- plant interfacethe role of root architectures for calculating root water uptake profiles. Hydrol. Earth Syst. Sci. Discuss., 6, 4233-4264. http:/www.hydrol-earth-syst-sci-discuss.net/6/4233/2009/

Valiantzas J.D., Kerkides P., Poulovassilis A. 1988. An improvement to the One-Step method for the determination of soil water diffusivities. Water Resour. Res. 24:1911-1920.

Valiantzas J.D. 1989. A simple approximate equation to calculate diffusivities from One-Step experiments. Soil Sci. Soc. Am. J. 53, 342349 .

Valiantzas J.D., Kerkides P. 1990. A simple iterative method for the simultaneous determination of soil hydraulic properties from OneStep outflow data. Water Resour. Res. 26:143-152.

Valiantzas J.D., Londra P.A., Sassalou A. 2007. Explicit formulae for soil water diffusivity using the Ona-Step outflow technique. Soil Sci. Soc. Am. J. 71:1685-1693.

Valiantzas J.D., Londra, P.A. 2012. Simplified equations for the determination of the hydraulic properties of horticultural substrates by One-Step outflow experiments. J. Plant Nutr. Soil Sci. 175:49-52.

Van Genuchten M.Th. 1980. A closed-form equation for predicting the hydraulic conductivity of unsaturated soils. Sci. Soc. Am. J. 44:892898.

Van Genuchten M.Th., Leij F.J. and Yates, S.R. 1991. The RETC code for quantifying the hydraulic functions of unsaturated soils. Robert $\mathrm{S}$. Kerr Environmental Research Laboratory Office of Research and Development, U.S. Environmental Protection Agency, ADA, Oklahoma 74820. 